\title{
Worldwide survey of neurologists on approach to autoimmune encephalitis
}

Aravind Ganesh, MD, DPhil, Luca Bartolini, MD, and Sarah F. Wesley, MD, MPH

Neurology: Clinical Practice April 2020 vol. 10 no. 2 140-148 doi:10.1212/CPJ.0000000000000701
Correspondence

Dr. Ganesh

aravindganeshy@yahoo.ca

\begin{abstract}
Objective

To explore practice differences in the diagnosis and management of autoimmune encephalitis $(\mathrm{AE})$, which is complicated by issues with sensitivity/specificity of antibody testing, nonspecific MRI/EEG/ CSF findings, and competing differential diagnoses.
\end{abstract}

\section{Methods}

We used a worldwide electronic survey with practice-related demographic questions and clinical questions about 2 cases: (1) a 20year-old woman with a neuropsychiatric presentation strongly suspicious of $\mathrm{AE}$ and (2) a 40-year-old man with new temporal lobe seizures and cognitive impairment. Responses among different groups were compared using multivariable logistic regression.

\section{Results}

We received 1,333 responses from 94 countries; $12.0 \%$ identified as neuroimmunologists. Case 1: those treating $>5 \mathrm{AE}$ cases per year were more likely to send antibodies in both serum and CSF (adjusted odds ratio [aOR] vs 0 per year: $3.29,95 \% \mathrm{CI}$ $1.31-8.28, p=0.011$ ), pursue empiric immunotherapy (aOR: 2.42, 95\% CI 1.33-4.40, $p=$ $0.004)$, and continue immunotherapy despite no response and negative antibodies at 2 weeks (aOR: 1.65, 95\% CI 1.02-2.69, $p=0.043$ ). Case 2: neuroimmunologists were more likely to send antibodies in both serum and CSF (aOR: 1.80, 95\% CI 1.12-2.90, $p=0.015$ ). Those seeing $>5 \mathrm{AE}$ cases per year (aOR: $1.86,95 \% \mathrm{CI} 1.22-2.86, p=0.004$ ) were more likely to start immunotherapy without waiting for antibody results.

\section{Conclusions}

Our results highlight the heterogeneous management of AE. Neuroimmunologists and those treating more $\mathrm{AE}$ cases generally take a more proactive approach to testing and immunotherapy than peers. Results highlight the need for higher-quality cohorts and trials to guide empiric immunotherapy, and evidence-based guidelines aimed at both experts and nonexperts. Because the average $\mathrm{AE}$ patient is unlikely to be first seen by a neuroimmunologist, ensuring greater uniformity in our approach to suspected cases is essential to ensure that patients are appropriately managed.

Autoimmune encephalitis $(\mathrm{AE})$ is a type of noninfectious neuroinflammation that is an increasingly recognized cause of acute or subacute progressive alteration in mental status with various presentations. Some cases are associated with specific autoantibodies to cell surface molecules and intracellular targets. ${ }^{1}$ However, antibody testing is not always available at many institutions, and results are of variable sensitivity and specificity, depending in part on the type of

Department of Clinical Neurosciences (AG), University of Calgary, Canada; Centre for Prevention of Stroke and Dementia (AG), University of Oxford, United Kingdom; Clinical Epilepsy Section (LB), National Institutes of Health, Bethesda, MD; and Department of Neurology (SFW), Yale School of Medicine, New Haven, CT.

Funding information and disclosures are provided at the end of the article. Full disclosure form information provided by the authors is available with the full text of this article at Neurology.org/cp. 
assay performed and on whether antibody testing is performed in both the serum and CSF or only in one or the other. ${ }^{2}$ The diagnostic process is complicated by new antibodies being identified at a rapid pace ${ }^{3,4}$ and known antibodies being identified in less characteristic cases, such as a first presentation of isolated psychosis. ${ }^{5}$ As antibody testing can often be negative, clinicians often must make a diagnosis using a combination of clinical phenotypes, neuroimaging, electroencephalography (EEG), and CSF results. To complicate matters, antibodymediated syndromes might not be associated with any evidence of inflammation in MRI and CSF studies in some patients, and EEG findings are often nonspecific. ${ }^{6}$ There are also several differential diagnoses to consider with AE-like presentations. ${ }^{2}$ Although some cases of suspected AE might respond positively to immunotherapy, this outcome is neither consistent nor specific to the diagnosis of AE-improvement with steroids, for example, often seen with lymphoma. ${ }^{7}$ There remains a paucity of high-quality diagnostic and treatment studies.

Given these uncertainties regarding the diagnosis and management of $\mathrm{AE}$, we recently interviewed experts from 3 different continents regarding the challenges of $\mathrm{AE}$ diagnosis and the role of antibody testing. ${ }^{8}$ Despite their different practice settings, all of them agreed that the diagnosis of $\mathrm{AE}$ should be driven primarily by the patient's clinical presentation and exclusion of key differential diagnoses, particularly infectious etiologies, and that workup should involve a thorough search for associated malignancies. They emphasized the importance of treating suspected $\mathrm{AE}$ cases with at least steroids while awaiting results of antibody testing. They agreed that antibody testing should be performed on both CSF and serum samples but cautioned against overreliance on these results. In particular, negative results for available antibodies would not dissuade them from treating patients with convincing presentations. This was in agreement with a recent position paper proposing a clinically grounded guideline for the diagnosis of $\mathrm{AE}^{2}$. However, consensus among experts does not always reflect the "ground reality" of how neurologists approach these cases.

Understanding how clinicians differ in their approach to complex diseases like $\mathrm{AE}$ can help inform not only further research but also educational initiatives and guideline development by highlighting enduring areas of uncertainty or clinical equipoise. Therefore, we explored practice differences in $\mathrm{AE}$ diagnosis and management using a worldwide electronic survey.

\section{Methods}

\section{Survey}

The survey was launched by the Practice Current section of Neurology: Clinical Practice (neurology.org/collection/ practice_current). We used an electronic survey that included 7 clinical and 8 demographic questions (appendix e-1, links.lww.com/CPJ/A113). The clinical questions pertained to 2 cases. Case 1 was deemed by 3 interviewed experts to be clinically convincing for autoimmune limbic encephalitis and consisted of a 20-year-old woman presenting with a neuropsychiatric syndrome, supportive brain MRI findings, and CSF lymphocytic pleocytosis. ${ }^{1}$ Respondents were asked whether they would send an autoantibody panel, and if so, in serum only or both serum and CSF. They were also asked whether they would start empiric treatment for AE with the autoantibody panel pending. Upon then being told that the panel has returned negative and the patient has still not improved with 2 weeks of first-line immunotherapy, respondents were asked whether they would continue immunotherapy (1stand/or 2nd-line agents) or stop.

Case 2 was more ambiguous and consisted of a 40-year-old man with new seizures, mild short-term memory impairment, right temporal lobe seizures, T2 hyperintensity in the right hippocampus, and negative infectious workup. However, the interviewed experts also deemed this case as suspicious enough for AE to warrant antibody testing and empiric immunotherapy. ${ }^{8}$ Respondents were asked whether they would send autoantibodies in the serum and/or CSF and whether they would start first-line immunotherapy. Those who did not start immunotherapy were asked if they would change their management, should the autoantibody panel return positive (low titer) for anti-NMDA receptor (NMDAR) antibodies in the serum and CSF in 2 weeks, with the patient experiencing focal seizures despite 2 adequately dosed antiepileptic drugs (AEDs).

Demographic questions included whether respondents identified as neuroimmunologists, the number of cases of $\mathrm{AE}$ they would treat per year, the population treated (adults/ children/both), years in practice, primary work setting, level of training, whether their practice was located in the United States or abroad, and in what US state or country. The survey was available online and was anonymous. Participation did not require membership in the American Academy of Neurology (AAN) or subscription to AAN journals. No compensation was offered. A link to the questionnaire was available in the Neurology ${ }^{\otimes}$ journals' webpages, in online ads and the print version of the journals, and in the Practice Current dedicated webpage. The survey was also advertised by the AAN and Neurology journals via social media. Individual internet protocol address was collected to ensure authenticity of responses. We opened the survey from November 28, 2017, to May 28, 2018, and all responses collected were included in the analysis.

\section{Statistical analysis}

The frequency of responses for each question/scenario was calculated for different demographic groups, focusing on (1) subspecialty status (neuroimmunologist vs not), (2) cases of AE treated over the past 12 months, (3) years in practice (trainee, $<10$-year experience, and $>10$-year experience), (4) practice population (children/adults/both), and (5) practice location (United States vs abroad). For case 1 , we examined the proportion of respondents in each 
We received 1,333 responses from 94 countries, of which 1,084 (81.3\%) were complete with all questions answered.

group who chose to (a) send an antibody panel, (b) send the panel in both serum and CSF (vs serum alone), (c) provide empiric immunotherapy without waiting for antibody results, and (d) continue immunotherapy despite no meaningful response to immunotherapy at 2 weeks and negative antibody testing. For case 2, we examined the proportion of respondents in each group who chose to (a) send an antibody panel in both serum and CSF, (b) provide empiric immunotherapy without waiting for antibody results, and (c) start immunotherapy (if initially not doing so) on being informed that the panel had returned with low-titer positive anti-NMDAR antibodies in the serum and CSF. For univariable analyses, we used the Fisher exact test. After identifying significant differences between the groups on univariable analysis, multivariable logistic regression was performed to adjust for all confounding variables, namely subspecialty status (neuroimmunologist vs not), $\mathrm{AE}$ cases per year (coded categorically as $0,1-5$, or $>5$ ), practice population (children/adults/both), and practice location (United States vs abroad).

Statistical significance was set at 2-sided $p<0.050$, except for subsequent $2 \times 2$ tests for significant associations in $3 \times 2$ tables, in which case significance was set at 2 -sided $p<0.017$ (Bonferroni correction $p=0.050 / 3$ ). All analyses were performed using STATA 13.1.

\section{Standard protocol approvals, registrations, and patient consents}

The study was certified as exempt from review by Children's National Medical Center Institutional Review Board.

\section{Data availability}

Anonymized data will be shared by request from any qualified investigator.

\section{Results}

We received 1,333 responses from 94 countries, of which $1,084(81.3 \%)$ were complete with all questions answered. The key respondent characteristics are shown in table 1.

\section{Case 1}

When presented case 1, 92.3\% of respondents chose to send an autoimmune antibody panel. On univariable analysis, the population treated and years in practice were associated with
Table 1 Characteristics of the survey respondents $(n=1,128)$

\begin{tabular}{|c|c|}
\hline Characteristic & $\mathrm{N}(\%)$ \\
\hline Neuroimmunologist & $135 / 1,128(12.0)$ \\
\hline $\begin{array}{l}\text { Cases of autoimmune encephalitis } \\
\text { treated per year }\end{array}$ & Available for 1,128 \\
\hline 0 & $213(18.9)$ \\
\hline $1-5$ & $713(63.2)$ \\
\hline $6-10$ & $142(12.6)$ \\
\hline $11-20$ & $38(3.4)$ \\
\hline$>20$ & $22(2.0)$ \\
\hline Patient population treated & Available for 1,125 \\
\hline Adults (aged $18 \mathrm{y}$ and older) & $938(83.4)$ \\
\hline Children (aged 0-18 y) & $46(4.1)$ \\
\hline Both adults and children & $141(12.5)$ \\
\hline Years in practice & Available for 1,126 \\
\hline Less than $10 \mathrm{y}$ & $401(35.6)$ \\
\hline 10 or more years & $395(35.1)$ \\
\hline In training & $330(29.3)$ \\
\hline Primary work setting & Available for 1,124 \\
\hline Hospital based & $901(80.2)$ \\
\hline Outpatient based & $223(19.8)$ \\
\hline Current level of training & Available for 1,123 \\
\hline $\begin{array}{l}\text { Attending/consultant/board-certified } \\
\text { faculty }\end{array}$ & $684(60.9)$ \\
\hline Resident/fellow & $439(39.1)$ \\
\hline Country of practice (top 10 ) & Available for 1,298 \\
\hline United States & $229(17.6)$ \\
\hline India & $103(7.9)$ \\
\hline Brazil & $82(6.3)$ \\
\hline Spain & $73(5.6)$ \\
\hline Italy & $63(4.9)$ \\
\hline United Kingdom & $50(3.9)$ \\
\hline Germany & $46(3.5)$ \\
\hline Canada & $38(2.9)$ \\
\hline Argentina & $32(2.5)$ \\
\hline China & $29(2.2)$ \\
\hline
\end{tabular}

the decision to send an antibody panel (table 2). On multivariable regression, those who reported treating more cases of $\mathrm{AE}$ in the past 12 months (adjusted odds ratio [aOR] for $>5$ cases per year vs $0: 3.29,95 \%$ CI $1.31-8.28, p=0.011$ ) were more likely to send antibodies, whereas those working 
Table 2 Autoantibody panel sent for case 1 (1,128 respondents)

\begin{tabular}{|c|c|c|c|}
\hline Demographic (total) & $\mathrm{N}(\%)$ & $p$ Value (Fisher exact) & $p$ Value (additional hypothesis tests) \\
\hline Neuroimmunologist & & 0.36 & \\
\hline Yes (135) & $129(95.6)$ & & \\
\hline No (993) & $924(93.1)$ & & \\
\hline Cases treated per year & & 0.12 & \\
\hline $0(213)$ & $192(90.1)$ & & \\
\hline $1-5(713)$ & $665(93.3)$ & & \\
\hline $6-10(142)$ & $138(97.2)$ & & \\
\hline $11-20(38)$ & $36(94.7)$ & & \\
\hline More than $20(22)$ & $21(95.5)$ & & \\
\hline Population treated & & $0.008^{a}$ & 0.022 adults vs both \\
\hline Adults (938) & $878(93.6)$ & & 0.11 adults vs children \\
\hline Both adults and children (141) & $124(87.9)$ & & $0.014^{\mathrm{a}}$ both vs children \\
\hline Children (46) & $46(100)$ & & \\
\hline Years in practice & & $0.038^{a}$ & \\
\hline In training $(330)$ & $304(92.1)$ & & 0.79 in-training vs $<10 \mathrm{y}$ \\
\hline Less than $10 \mathrm{y}(401)$ & $367(91.5)$ & & $0.020<10$ y vs $\geq 10 y$ \\
\hline 10 or more years (395) & $378(95.7)$ & & 0.057 in-training vs $>10 \mathrm{y}$ \\
\hline Level of training & & $0.039^{a}$ & \\
\hline Attending/consultant (684) & $646(94.4)$ & & \\
\hline Resident/fellow (439) & $400(91.1)$ & & \\
\hline In the United States & & 0.19 & \\
\hline Yes (229) & $318(95.2)$ & & \\
\hline No (865) & 801 (92.6) & & \\
\hline
\end{tabular}

${ }^{a}$ Significant $p$ values are indicated.

with both adults/children were less likely to do so than those working with adults alone (aOR: 0.46, 95\% CI 0.25-0.84, $p=0.011$, table e-1, links.lww.com/CPJ/A112).

Of those choosing to send an autoantibody panel, $91.6 \%$ chose to send the panel in both serum and CSF, whereas $8.4 \%$ chose to send it in the serum alone. On univariable analysis, respondents working with children were more likely to send antibodies in both serum and CSF rather than just serum compared with those working with both adults and children (table 3). However, on multivariable regression, no associations were found with this decision; respondents working with children alone were "dropped" because they all favored sending antibodies in both serum and CSF (table e-2, links. lww.com/CPJ/A112).

Of note, $85.1 \%$ of those choosing to send a panel said that they would treat the patient empirically for presumed $\mathrm{AE}$, whereas 9.2\% said that they would wait for the antibody panel to come back and treat only if it was positive at least in the serum, and 3.2\% said that they would treat only if it was positive in both serum and CSF. Of note, $2.4 \%$ suggested alternative plans, including starting acyclovir $(\mathrm{n}=12)$ or treating both with acyclovir and immunotherapy $(n=5)$. Although respondents were told that extended toxicology testing, CT of the chest/abdomen/pelvis, and extensive infectious workup were negative, a few wanted additional investigations before deciding on immunotherapy, such as obtaining EEG to look for supportive patterns like extreme delta brush $(n=2)$, further exclusion of infectious causes particularly herpes $(n=6)$, and a pelvic ultrasound to rule out ovarian teratoma $(\mathrm{n}=2)$. A few others reported that their choice would depend on factors such as clinical disability $(n=2)$ or presence of additional signs like refractory seizures $(\mathrm{n}=2)$. On univariable analysis, the number of $\mathrm{AE}$ cases managed annually (per respondent report) was associated with the decision to start empiric immunotherapy while awaiting antibody results (table 4). On multivariable regression, the number of $\mathrm{AE}$ cases per year remained associated with the decision to pursue empiric 
Table 3 Autoantibody panel sent in both serum and CSFvs serum alone for case 1, among those choosing to send a panel (1,053 respondents)

\begin{tabular}{|c|c|c|c|}
\hline Demographic (total) & $\mathrm{N}(\%)$ & $p$ Value (Fisher exact) & $p$ Value (additional hypothesis tests) \\
\hline Neuroimmunologist & & 0.73 & \\
\hline Yes (129) & $120(93.0)$ & & \\
\hline No (924) & $847(91.7)$ & & \\
\hline Cases treated per year & & 0.23 & \\
\hline $0(192)$ & $177(92.2)$ & & \\
\hline $1-5(665)$ & $614(92.3)$ & & \\
\hline $6-10(138)$ & $120(87.0)$ & & \\
\hline $11-20(36)$ & $35(97.2)$ & & \\
\hline More than $20(21)$ & $20(95.2)$ & & \\
\hline Population treated & & $0.033^{\mathrm{a}}$ & \\
\hline Adults (878) & $806(91.8)$ & & 0.23 adults vs both \\
\hline Both adults and children (124) & $110(88.7)$ & & $0.012^{\mathrm{a}}$ both vs children \\
\hline Children (46) & $46(100)$ & & 0.043 adults vs children \\
\hline Years in practice & & 0.70 & \\
\hline In training (304) & $281(92.4)$ & & \\
\hline Less than $10 \mathrm{y}(367)$ & $333(90.7)$ & & \\
\hline 10 or more years (378) & $348(92.1)$ & & \\
\hline Level of training & & 0.56 & \\
\hline Attending/consultant (646) & $590(91.3)$ & & \\
\hline Resident/fellow (400) & $370(92.5)$ & & \\
\hline In the United States & & 0.053 & \\
\hline Yes (218) & $207(95.0)$ & & \\
\hline No (801) & 728 (90.9) & & \\
\hline
\end{tabular}

${ }^{\text {a }}$ Significant $p$ values are indicated.

immunotherapy (aOR for $1-5$ per year vs 0: $2.31,95 \%$ $1.51-3.51, p<0.001$; $>5$ per year: aOR: $2.42,95 \%$ CI $1.33-4.40$, $p=0.004$, table e-3, links.lww.com/CPJ/A112).

If no meaningful improvement at 2 weeks with first-line immunotherapy and antibody panel negative in CSF and serum, 577/970 (59.5\%) who favored empiric therapy said that they would continue immunotherapy (first- and secondline agents), whereas 367 (37.8\%) said that they would stop immunotherapy and reassess for other causes. Of note, $2.7 \%$ proposed alternatives, including both continuing immunotherapy while reassessing for other causes $(n=12)$, repeating the lumbar puncture perhaps with extended antibody screening $(\mathrm{n}=4)$, additional body cancer screening or consideration of brain biopsy $(n=2)$, long-term EEG monitoring $(n=1)$, waiting longer for delayed treatment effect before continuing $(n=1)$, or considering oophorectomy $(\mathrm{n}=1)$. On univariable analysis, the number of $\mathrm{AE}$ cases per year was associated with the decision to continue immunotherapy despite no response at 2 weeks and negative antibody testing (table 5). On multivariable regression, respondents who reported seeing $>5 \mathrm{AE}$ cases per year were more likely to persist with immunotherapy (aOR: 1.65, 95\% CI 1.02-2.69, $p=0.043$, table e-4, links.lww.com/CPJ/A112).

\section{Case 2}

For case 2, 846/1,237 (68.4\%) chose to send antibodies in both serum and CSF, 117 (9.5\%) in serum alone, whereas $264(21.3 \%)$ chose not to send antibodies. Ten $(0.8 \%)$ had independent responses including that they would only send antibodies if there was CSF leukocytosis $(n=3)$ or supportive features like contrast enhancement on MRI $(n=1)$, or refractory or exceptionally frequent seizures $(n=2)$. Three said that they would wait for herpes virus PCR to return negative. One respondent indicated that most of the time they could not afford antibody testing. On univariable analysis, respondents identifying as neuroimmunologists 
Table 4 Empiric immunotherapy chosen in case 1 (1,147 respondents)

\begin{tabular}{|c|c|c|}
\hline Demographic (total) & N (\%) & $\begin{array}{l}p \text { Value } \\
\text { (Fisher exact) }\end{array}$ \\
\hline Neuroimmunologist & & 0.34 \\
\hline Yes (129) & $115(89.2)$ & \\
\hline No (924) & $790(85.5)$ & \\
\hline Cases treated per year & & $0.001^{a}$ \\
\hline $0(192)$ & $145(75.5)$ & \\
\hline $1-5(665)$ & $585(88.0)$ & \\
\hline $6-10(138)$ & $121(87.7)$ & \\
\hline $11-20(36)$ & $32(88.9)$ & \\
\hline More than $20(21)$ & $20(95.2)$ & \\
\hline Population treated & & 0.98 \\
\hline Adults (878) & $755(86.0)$ & \\
\hline Both adults and children (124) & $106(85.5)$ & \\
\hline Children (46) & $40(87.0)$ & \\
\hline Years in practice & & 0.10 \\
\hline In training (304) & $251(82.6)$ & \\
\hline Less than 10 y (367) & $324(88.3)$ & \\
\hline 10 or more years (378) & $327(86.4)$ & \\
\hline Level of training & & 0.36 \\
\hline Attending/consultant (646) & $561(86.8)$ & \\
\hline Resident/fellow (400) & $339(84.8)$ & \\
\hline In the United States & & 0.44 \\
\hline Yes (218) & $184(84.4)$ & \\
\hline No (801) & $692(86.4)$ & \\
\hline
\end{tabular}

were more likely to send off antibodies in the serum and CSF ( $p=0.003$, table 6). On multivariable regression, identifying as a neuroimmunologist remained associated with sending antibodies in both serum and CSF (aOR: 1.80, 95\% CI 1.12-2.90, $p=0.015$, table e-5, links.lww.com/CPJ/A112).

When asked whether they would consider empiric immunotherapy, only 498 (40.3\%) said that they would do so at this time, whereas 355 (28.7\%) said that they would only do so if the antibody panel came back positive. Three hundred fifty-seven (28.9\%) said that they would not treat. Twenty seven $(2.2 \%)$ had independent responses including starting acyclovir $(\mathrm{n}=4)$, starting both acyclovir and steroids $(\mathrm{n}=1)$, ruling out infectious or CNS/body neoplastic processes $(n=4)$, only if refractory to antiepileptic drugs $(n=5), C S F$ suggestive of autoimmunity with oligoclonal bands, elevated protein, and/or pleocytosis $(n=6)$, or pending the development of new symptoms or signs $(n=1)$. On
Table 5 Continued immunotherapy despite no meaningful response to immunotherapy at 2 weeks and negative antibody testing in case 1 (970 respondents)

\begin{tabular}{lll}
\hline Demographic (total) & $\mathrm{N}(\%)$ & $\begin{array}{l}p \text { Value } \\
\text { (Fisher exact) }\end{array}$ \\
\hline Neuroimmunologist & 0.10 \\
\hline Yes (113) & $76(67.3)$ & \\
\hline No (790) & $467(59.1)$ & \\
\hline Cases treated per year & & \\
\hline 0 (143) & $75(52.5)$ & \\
\hline 1-5 (585) & $355(60.7)$ & \\
\hline 6-10 (121) & $79(65.3)$ & \\
\hline 11-20 (32) & $24(75.0)$ & \\
\hline More than 20 (20) & $9(45.0)$ & \\
\hline Population treated & $105(57.1)$ & \\
\hline Adults (755) & $422(61.2)$ & \\
\hline Both adults and \\
children (104)
\end{tabular}

${ }^{a}$ Significant $p$ values are indicated.

univariable analysis, respondents living outside the United States ( $p=0.016)$ were more likely to choose immunotherapy without waiting for antibody results, and the number of $\mathrm{AE}$ cases per year was also associated with this decision $(p=0.040$, table 7$)$. On multivariable regression, seeing more $\mathrm{AE}$ cases per year and living outside the United States remained associated with choosing immunotherapy without waiting for antibody results (table e-6, links.lww.com/CPJ/A112).

On being informed that the antibody panel returned with low-titer positive anti-NMDAR antibodies in the serum and CSF while the patient was continuing to have focal seizures despite 2 appropriately dosed AEDs, 50/120 (41.7\%) who initially said that they would not treat then said that they would 
Because the typical patient with $A E$ is unlikely to be seen first by

a neuroimmunologist, ensuring greater uniformity in our approach to suspected cases is essential.

treat with immunotherapy; 60 (50.0\%) additionally said that they would make changes to the AEDs besides starting immunotherapy. Ten (8.3\%) said that they would only change AEDs. On univariable analysis, living outside the United States was associated with choosing immunotherapy $(p=0.04)$; $100 \%$ of those who reported seeing $>5 \mathrm{AE}$ cases per year chose immunotherapy vs $76.2 \%$ of those reporting zero cases per year $(p=0.058$, table e-7, links.lww.com/CPJ/A112). On multivariable regression, seeing more $\mathrm{AE}$ cases per year was associated with choosing immunotherapy with positive antibody results (aOR for $1-5$ per year vs 0: aOR: 5.55 , 95\% CI 1.03-29.8, $p=0.046$, table e-8, links.lww.com/CPJ/A112).

\section{Discussion}

In a large Practice Current worldwide survey of neurologists using representative cases, we identified considerable heterogeneity in the diagnosis and management of $\mathrm{AE}$. In particular, neuroimmunologists and those treating more $\mathrm{AE}$ cases per year generally took a more proactive approach to testing and immunotherapy than peers. Our findings have implications for guideline development and educational initiatives, the design of future large-scale cohorts or trials of $\mathrm{AE}$, and for estimates of $\mathrm{AE}$ prevalence.

First, the considerable differences in approach between different groups of physicians, particularly between those identifying as neuroimmunologists vs as nonneuroimmunologists and between those encountering $\mathrm{AE}$ more vs less often, highlight the importance of further educational initiatives and evidence-based guidelines aimed at both experts and nonexperts. Both cases in our survey were deemed by interviewed experts to be suspicious enough for $\mathrm{AE}$ to warrant antibody testing and empiric immunotherapy, ${ }^{8}$ but clearly this opinion was not unanimous among survey respondents. This lack of uniformity is worrisome, as observational data indicate that $\mathrm{AE}$ can leave $20 \%$ of patients dependent for daily activities and that early treatment is a key predictor of good outcome. ${ }^{9}$ Because the typical patient with $\mathrm{AE}$ is unlikely to be seen first by a neuroimmunologist, ensuring greater uniformity in our approach to suspected cases is essential to ensure that patients are appropriately managed and investigated for this potentially devastating disease. The absolute difference in responses between those identifying as neuroimmunologists vs nonneuroimmunologists was much smaller for the less ambiguous
Table 6 Antibody panel sent in both serum and CSF in case 2 (1,237 respondents)

\begin{tabular}{|c|c|c|}
\hline Demographic (total) & $\mathrm{N}(\%)$ & $\begin{array}{l}p \text { Value } \\
\text { (Fisher exact) }\end{array}$ \\
\hline Neuroimmunologist & & $0.003^{a}$ \\
\hline Yes (135) & $108(80.0)$ & \\
\hline No (993) & $670(67.5)$ & \\
\hline Cases treated per year & & 0.063 \\
\hline $0(213)$ & $134(62.9)$ & \\
\hline $1-5(713)$ & $490(68.7)$ & \\
\hline $6-10(142)$ & $108(76.1)$ & \\
\hline $11-20(38)$ & $28(73.7)$ & \\
\hline More than 20 (22) & $18(81.8)$ & \\
\hline Population treated & & 0.79 \\
\hline Adults (938) & $645(68.8)$ & \\
\hline Both adults and children (141) & $98(69.5)$ & \\
\hline Children (46) & 34 (73.9) & \\
\hline Years in practice & & 0.78 \\
\hline In training $(330)$ & $232(70.3)$ & \\
\hline Less than $10 \mathrm{y}(401)$ & $276(68.8)$ & \\
\hline 10 or more years (395) & $268(67.9)$ & \\
\hline Level of training & & 0.086 \\
\hline Attending/consultant (684) & $459(67.1)$ & \\
\hline Resident/fellow (439) & $316(72.0)$ & \\
\hline In the United States & & 0.52 \\
\hline Yes (229) & $153(66.8)$ & \\
\hline No (865) & $597(69.0)$ & \\
\hline
\end{tabular}

a Significant $p$ values are indicated.

case 1 - which was very much in keeping with NMDAR antibody encephalitis ${ }^{1}$ - and may reflect greater awareness of one form of $\mathrm{AE}$ among neurologists, encouragingly indicating the potential effectiveness of education in this regard.

Second, the areas of relative disagreement identified by our survey may help inform the design of future large-scale cohorts or trials in $\mathrm{AE}$, which need to be based on an understanding of practice patterns and attitudes of physician stakeholders to successfully recruit patients and help resolve practical uncertainties. In particular, it is unclear what the threshold should be to send an autoimmune panel and use immunotherapy in patients with newonset, imaging-negative temporal lobe epilepsy, as in case 2. Although neuroimmunologists were more likely to send testing, this is not necessarily the most pragmatic or cost-effective option. Future cohort studies should assess the yield of testing such undifferentiated cases and the risks/benefits of early treatment vs 
Table 7 Empiric immunotherapy chosen in case 2 without waiting for antibody results $(1,237$ respondents)

\begin{tabular}{lll}
\hline Demographic (total) & N (\%) & $\begin{array}{l}p \text { Value } \\
\text { (Fisher exact) }\end{array}$ \\
\hline Neuroimmunologist & $59(43.7)$ & 0.51 \\
\hline Yes (135) & $402(40.5)$ & \\
\hline No (993) & & $0.040^{\text {a }}$ \\
\hline Cases treated per year & $69(32.4)$ & \\
\hline 0 (213) & $299(41.9)$ & \\
\hline 1-5 (713) & $67(47.2)$ & \\
\hline 6-10 (142) & $16(42.1)$ & \\
\hline 11-20 (38) & $11(50.0)$ & \\
\hline More than 20 (22) & & \\
\hline Population treated & $372(43.0)$ & \\
\hline Adults (938) & $387(41.3)$ & \\
\hline Both adults and children (141) & $62(44.0)$ & \\
\hline Children (46) & $14(30.4)$ & \\
\hline Years in practice & $163(41.3)$ & \\
\hline In training (330) & & \\
\hline Less than 10 y (401) & & \\
\hline 10 or more years (395) & & \\
\hline Level of training & & \\
\hline Attending/consultant (684) & & \\
\hline Resident/fellow (439) & & \\
\hline In the United States & & \\
\hline No (865) & & \\
\hline
\end{tabular}

${ }^{\text {a }}$ Significant $p$ values are indicated.

waiting for positive antibody results. There is also the challenge of identifying patients presenting with psychotic or other neuropsychiatric symptoms who may warrant further investigation for AE. For example, in NMDAR antibody encephalitis, central psychopathologic features of mood and psychotic disorders consistently coexist within individual patients, although wellcontrolled prospective studies are needed to further advance this approach. ${ }^{10}$ The definition of acceptable treatment delay and "red flag" symptoms also requires further evidence-based clarification. For example, a recent cohort study found that delays to treatment longer than 4 weeks and lack of improvement in that time frame were both independently associated with poor 1-year functional outcome, in addition to intensive care unit admission, abnormal MRI, and CSF white blood cell count $>20$ cells $/ \mu \mathrm{L} .{ }^{11}$ A smaller retrospective cohort study found that treatment delays shorter than 60 days and the absence of status epilepticus were associated with better cognitive performance over a year after symptom onset. ${ }^{12}$ It may very well turn out that antibody testing is best reserved for patients with additional concerning features like status epilepticus, unambiguous cognitive impairment, or psychiatric manifestations and that waiting 2 weeks for more evidence from antibody results does not dramatically change outcomes.

Third, the apparent discrepancies in our approach to AE cases will contribute to inaccurate estimates of the incidence/prevalence of $\mathrm{AE}$ and response to treatment, particularly if such data are derived from physician diagnostic codes or other administrative data. For example, missed cases of $\mathrm{AE}$ can lead to underestimates of incidence/prevalence, whereas overzealous diagnoses can lead to additional erroneous labels of immunotherapy failure. This can in turn compromise decisions about resource allocation and the development of AE treatment protocols. These challenges further emphasize the need for high-quality cohort studies that ideally incorporate direct clinical evaluations or at least comprehensive review of patient records guided by diagnostic criteria. ${ }^{13}$

Although our analysis has several strengths, including a large worldwide sample and representation of neurologists across specialties and levels of experience, there are important shortcomings. First, we could not represent the full spectrum of $\mathrm{AE}$ presentations and diagnostic/treatment conundrums needed for more granular analyses of physician decision making. The cases presented may not be generalizable to all practice settings. However, we chose to limit this survey to 2 cases in the interest of maximizing brevity and survey completion. Second, our surveybased study is vulnerable to selection bias; for instance, respondents more interested in autoimmune neurology may have been overrepresented. Third, respondents may have been biased by us framing the survey as related to $\mathrm{AE}$, which may have resulted in an overestimate of the proportion of respondents who would investigate and treat the cases as AE. Fourth, we cannot be confident whether respondents chose an option because they thought it was the best course of action or because it seemed most feasible within their practice. Fifth, because we did not contact respondents ourselves, we could not verify the veracity of respondents' qualifications. However, by not limiting respondents to our network, we were able to capture a greater diversity of respondents.

In conclusion, our results highlight the heterogeneous management of $\mathrm{AE}$, the need for higher-quality cohorts and trials to guide empiric immunotherapy, and call for evidencebased guidelines aimed at both experts and nonexperts.

\section{Study funding}

No targeted funding reported.

\section{Disclosure}

A. Ganesh is a member of the editorial team of Neurology; has received speaker honoraria from The Meritas Seminar Series, Oxford; has served as a consultant for Adkins Research Group and Genome BC; has received research support from The Rhodes Trust and Wellcome Trust; and holds stock/stock 
options from SnapDx, TheRounds.ca, and Advanced Health Analytics (AHA Health Ltd). L. Bartolini is a Section Editor for Neurology Clinical Practice. Dr. Bartolini is an employee of the federal government. This manuscript was not a term of his employment, nor did he receive any compensation for the manuscript. S.F. Wesley has been a member of the editorial staff of the Resident and Fellow Section of Neurology. Full disclosure form information provided by the authors is available with the full text of this article at Neurology.org/cp.

\section{Publication history}

Received by Neurology: Clinical Practice March 7, 2019. Accepted in final form May 16, 2019.

\section{Appendix Authors}

\begin{tabular}{lll}
\hline Name & Location & Contribution \\
\hline $\begin{array}{l}\text { Aravind } \\
\text { Ganesh, MD, } \\
\text { DPhil }\end{array}$ & $\begin{array}{l}\text { University of Calgary, } \\
\text { Calgary, Canada; } \\
\text { University of Oxford, } \\
\text { Oxford, United Kingdom }\end{array}$ & $\begin{array}{l}\text { Involved in the conception } \\
\text { and design of the study, } \\
\text { analyzed the data, and } \\
\text { wrote and revised the } \\
\text { manuscript }\end{array}$ \\
$\begin{array}{lll}\text { Luca Bartolini, } \\
\text { MD }\end{array}$ & $\begin{array}{l}\text { National Institutes of } \\
\text { Health, Bethesda, MD }\end{array}$ & $\begin{array}{l}\text { Involved in the conception } \\
\text { and design of the study, } \\
\text { dissemination of the survey, } \\
\text { acquisition of the data, and } \\
\text { revision of the manuscript }\end{array}$ \\
\hline $\begin{array}{l}\text { Sarah F. Wesley, } \\
\text { MD, MPH }\end{array}$ & $\begin{array}{l}\text { Yale School of Medicine, } \\
\text { New Haven, CT }\end{array}$ & $\begin{array}{l}\text { Involved in the conception, } \\
\text { writing, and revision of the } \\
\text { manuscript. }\end{array}$ \\
\hline
\end{tabular}

\section{References}

1. Dalmau J, Geis C, Graus F. Autoantibodies to synaptic receptors and neuronal cell surface proteins in autoimmune diseases of the central nervous system. Physiol Rev 2017;97:839-887.

2. Graus F, Titulaer MJ, Balu R, et al. A clinical approach to diagnosis of autoimmune encephalitis. Lancet Neurol 2016;15:391-404.

3. Gresa-Arribas N, Planaguma J, Petit-Pedrol M, et al. Human neurexin-3alpha antibodies associate with encephalitis and alter synapse development. Neurology 2016; $86: 2235-2242$.

4. Sabater L, Gaig C, Gelpi E, et al. A novel non-rapid-eye movement and rapid-eyemovement parasomnia with sleep breathing disorder associated with antibodies to IgLON5: a case series, characterisation of the antigen, and post-mortem study. Lance Neurol 2014;13:575-586.

5. Kayser MS, Titulaer MJ, Gresa-Arribas N, Dalmau J. Frequency and characteristics of isolated psychiatric episodes in anti-N-methyl-d-aspartate receptor encephalitis. JAMA Neurol 2013;70:1133-1139.

6. Escudero D, Guasp M, Arino $\mathrm{H}$, et al. Antibody-associated CNS syndromes without signs of inflammation in the elderly. Neurology 2017;89:1471-1475.

7. Porter AB, Giannini C, Kaufmann T, et al. Primary central nervous system lymphoma can be histologically diagnosed after previous corticosteroid use: a pilot study to determine whether corticosteroids prevent the diagnosis of primary central nervous system lymphoma. Ann Neurol 2008;63:662-667.

8. Ganesh A, Wesley SF. Practice Current: when do you suspect autoimmune encephalitis and what is the role of antibody testing? Neurol Clin Pract 2018;8. $67-73$.

9. Titulaer MJ, McCracken L, Gabilondo I, et al. Treatment and prognostic factors for long-term outcome in patients with anti-NMDA receptor encephalitis: an observational cohort study. Lancet Neurol 2013;12:157-165.

10. Al-Diwani A, Handel A, Townsend L, et al. The psychopathology of NMDARantibody encephalitis in adults: a systematic review and phenotypic analysis of individual patient data. Lancet Psychiatry 2019;6:235-246.

11. Balu R, McCracken L, Lancaster E, Graus F, Dalmau J, Titulaer MJ. A score that predicts 1-year functional status in patients with anti-NMDA receptor encephalitis. Neurology 2019;92:e244-e252.

12. Hebert J, Day GS, Steriade C, Wennberg RA, Tang-Wai DF. Long-term cognitive outcomes in patients with autoimmune encephalitis. Can J Neurol Sci 2018;45: $540-544$.

13. Dubey D, Pittock SJ, Kelly CR, et al. Autoimmune encephalitis epidemiology and a comparison to infectious encephalitis. Ann Neurol 2018;83:166-177.

\section{Share Your Insights, Expertise, and Experiences}

- How are you employing drugs and devices in your field?

- What ethical challenges do you face?

- Do you have a case report that is illustrative of a clinical challenge?

- What challenges have you faced or successes have you enjoyed in bringing greater efficiency to your practice?

Deliver a high-quality, peer-reviewed message to your colleagues in practice, submit your paper at NPub.org/NCP/submit. 


\title{
Neurology ${ }^{\circ}$ Clinical Practice
}

\author{
Worldwide survey of neurologists on approach to autoimmune encephalitis \\ Aravind Ganesh, Luca Bartolini and Sarah F. Wesley \\ Neurol Clin Pract 2020;10;140-148 Published Online before print August 13, 2019 \\ DOI 10.1212/CPJ.0000000000000701
}

This information is current as of August 13, 2019

\begin{tabular}{|c|c|}
\hline $\begin{array}{l}\text { Updated Information \& } \\
\text { Services }\end{array}$ & $\begin{array}{l}\text { including high resolution figures, can be found at: } \\
\text { http://cp.neurology.org/content/10/2/140.full.html }\end{array}$ \\
\hline References & $\begin{array}{l}\text { This article cites } 13 \text { articles, } 1 \text { of which you can access for free at: } \\
\text { http://cp.neurology.org/content/10/2/140.full.html\#\#ref-list-1 }\end{array}$ \\
\hline Citations & $\begin{array}{l}\text { This article has been cited by } 4 \text { HighWire-hosted articles: } \\
\text { http://cp.neurology.org/content/10/2/140.full.html\#\#otherarticles }\end{array}$ \\
\hline Subspecialty Collections & $\begin{array}{l}\text { This article, along with others on similar topics, appears in the } \\
\text { following collection(s): } \\
\text { All Cognitive Disorders/Dementia } \\
\text { http://cp.neurology.org//cgi/collection/all_cognitive_disorders_dementi } \\
\text { a } \\
\text { Autoimmune diseases } \\
\text { http://cp.neurology.org//cgi/collection/autoimmune_diseases } \\
\text { Encephalitis } \\
\text { http://cp.neurology.org//cgi/collection/encephalitis } \\
\text { Practice Current } \\
\text { http://cp.neurology.org//cgi/collection/practice_current }\end{array}$ \\
\hline Permissions \& Licensing & $\begin{array}{l}\text { Information about reproducing this article in parts (figures,tables) or in } \\
\text { its entirety can be found online at: } \\
\text { http://cp.neurology.org/misc/about.xhtml\#permissions }\end{array}$ \\
\hline Reprints & $\begin{array}{l}\text { Information about ordering reprints can be found online: } \\
\text { http://cp.neurology.org/misc/addir.xhtml\#teprintsus }\end{array}$ \\
\hline
\end{tabular}

\section{Updated Information \&}

References

\section{Citations}

\section{Subspecialty Collections}

Reprints including high resolution figures, can be found at:

This article cites 13 articles, 1 of which you can access for free at:

This article has been cited by 4 HighWire-hosted articles:

This article, along with others on similar topics, appears in the following collection(s):

All Cognitive Disorders/Dementia

Autoimmune diseases

Aut///cp.neurology.or

Practice Current

Information about reproducing this article in parts (figures,tables) or in its entirety can be found online at:

Neurol Clin Pract is an official journal of the American Academy of Neurology. Published continuously since 2011, it is now a bimonthly with 6 issues per year. Copyright (C) 2019 American Academy of Neurology. All rights reserved. Print ISSN: 2163-0402. Online ISSN: 2163-0933.

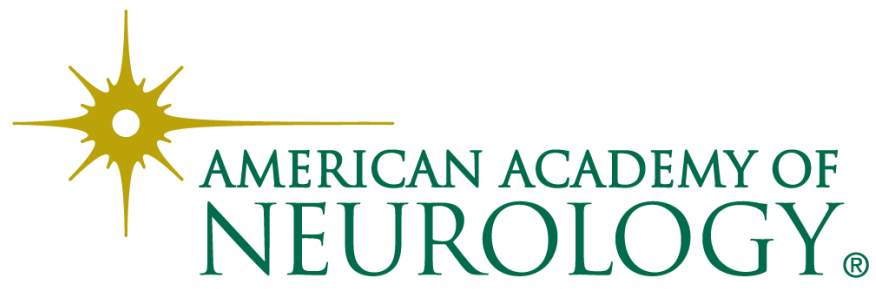

